\title{
Effect of Wells' Connectivity Enhancement on the Performance of Vapor Extraction (VAPEX) Process
}

\author{
Mehdi Mohammadpoor and Farshid Torabi* \\ Petroleum Systems Engineering, Faculty of Engineering and Applied Science, University of Regina, Regina, SK, S4S OA2 - Canada \\ e-mail: mohammme@uregina.ca-farshid.torabi@uregina.ca \\ * Corresponding author
}

\begin{abstract}
Drawbacks of the thermal recovery techniques such as excessive heat loss to the surrounding formations and carbon dioxide emissions during these processes have directed the interests of researchers towards more viable alternatives such as solvent-based recovery techniques (e.g. VAPEX). One of the key parameters to implement a successful VAPEX process is to control the profiles of vapour chamber and consequently improve the areal sweep efficiency. In this regard, an optimum well configuration and well connectivity establishment between the injection and production wells are desirable. The main focus of this research is to extensively conduct series of experiments to investigate the effect of injection/production wells connectivity on the performance of VAPEX process. For this purpose, two large-scale physical models were employed. Propane and propane/carbon dioxide mixtures were selected as the injection solvents in the visual sand-packed physical models saturated with heavy oil sample from Saskatchewan (Canada) heavy oil. Various injection/production scenarios were followed and it was found that the initial connection path between the injector and producer had a significant impact on the vapour chamber profiles and consequently on the ultimate recovery performance of the VAPEX process.
\end{abstract}

Résumé - Influence de l'amélioration de la connectivité des puits sur la performance du processus d'extraction à la vapeur (VAPEX) - Les inconvénients des techniques de récupération thermique, tels que la déperdition excessive de chaleur vers les formations environnantes et les émissions de dioxyde de carbone pendant ce processus, ont dirigé l'attention des chercheurs vers des alternatives plus viables comme les processus de récupération à base de solvant (e.g. VAPEX). Pour mettre en œuvre un processus VAPEX concluant, un des paramètres clés est de contrôler les formes de la chambre à vapeur et donc d'améliorer le balayage surfacique. À cet égard, une configuration optimum du puits ainsi que la création d'une connectivité entre les puits d'injection et de production sont souhaitables. Le point principal de la présente recherche consiste à effectuer une série d'expériences afin d'examiner l'effet de la connectivité des puits d'injection/production sur la performance du processus VAPEX. À cette fin, on a utilisé deux modèles physiques à grande échelle. On a choisi du propane et des mélanges de propane/dioxyde de carbone comme solvants d'injection dans les modèles physiques visuels faits de sable compacté et saturé d'un échantillon de pétrole lourd du Saskatchewan (Canada). On a suivi divers scénarios injection/production et on a découvert que la voie de connexion initiale entre injecteur/producteur avait un impact important sur les formes de la chambre à vapeur et, par conséquent, sur la performance ultime de récupération du processus VAPEX. 


\section{INTRODUCTION}

The application of numerous heavy oil recovery techniques has led to the recovery of small portions of this oil. Increasing the capillary number and/or lowering the mobility ratio are the basic principles of Enhanced Oil Recovery (EOR) methods. EOR processes are mainly divided into four categories: thermal, gas, chemical, and other. In addition, oilproduction from EOR projects continues to supply an increasing percentage of the world's oil. About $3 \%$ of the worldwide production now comes from EOR processes. Therefore, the importance of choosing the most feasible recovery technique becomes increasingly important to petroleum engineers. VAPEX is an energy-efficient method of recovering high viscosity heavy oil and bitumen from reservoirs. The process uses a solvent in the miscible displacement of bitumen or heavy crude oil. VAPEX improves energy efficiency and reduces emissions and operating costs. However, production rates with this process are lower than with traditional steam processes. In conventional VAPEX process, a mixture of vapourized solvent (propane and/or butane) and a commercially available non-condensable gas (methane, natural gas) is injected into the reservoir to reduce oil viscosity. While the VAPEX process became less attractive with the increase of gas price, injecting $\mathrm{CO}_{2}$ will decrease solvent cost. Moreover, $\mathrm{CO}_{2}$ is more soluble in heavy oils than methane. On the other hand, this can be environmentally important because nowadays $\mathrm{CO}_{2}$ sequestration itself is an important environmental issue.

Yazdani and Maini (2005) did a scale-up for the VAPEX method and studied the effects of drainage height and grain size on production rates in the VAPEX process. In their research, it was found that minor changes in heavy oil composition do not significantly affect the observed drainage rates. It was also observed that scaled-up, stabilized oildrainage rates are much higher than the predictions published in the literature. Thus, the VAPEX process may be more widely applicable than previously thought (Yazdani, 2007; Yazdani and Maini, 2005).

The idea of injecting the solvent vapours to enhance the oil recovery was first proposed in 1974 by Allen (Allen, 1974, 1976; James et al., 2007), in which, the Cyclic Steam Stimulation (CSS) process was varied by alternating steam and solvent. Because of the low oil recovery, the idea was not field tested. Later, Allen (1976) improved the idea by injecting a mixture of two gases: one gas as the carrier gas and the other one as the solvent. This idea was further improved and VAPEX was introduced later by Butler and Mokrys (1989, 1991). As an injected solvent, propane is common in VAPEX studies. After all, Das and Butler found propane and butane to be the most effective solvents for VAPEX (Das, 1995). They found that propane diffuses faster and produces higher production rates. On the other hand, it has been found that dispersion coefficient and solubility of propane increase with a decrease in the permeability of the porous media (Abukhalifeh et al., 2011). In the first step of the VAPEX, the solvent is injected through the injector to form an initially vertical solvent vapour chamber between the injector and the producer. The vapour chamber then spreads, and gravity stabilizes the oil-solvent interface. Here, molecular diffusion of solvent vapour into the bitumen controls drainage (Butler and Mokrys, 1991; Butler and Jiang, 1996, 2000). Thus, in order to maximize solvent vapour contact with the reservoir, the injection and production wells should be drilled horizontally. There are two types of gravity drainage flow during the VAPEX process: boundary drainage and transition film drainage (Roopa and Dawe, 2007). In fact, Roopa and Dawe (2007) found that the rate of film drainage that occurs in the three-phase flow processes within the vapour chamber depends on the effects of temperature on viscosity, diffusion coefficients, mass transfer, interfacial tension, and wettability.

Additionally, VAPEX has lots of environmental advantages. Luhning et al. (2003) did a comprehensive literature on the environmental advantages of VAPEX and they concluded that due to the in situ upgrading that takes place during the VAPEX process, there will be less asphaltene in the produced oil. This means less energy is needed for the transportation of heavy oil in pipelines as well as less maintenance costs for the pipelines and facilities. This will consequently decrease the future emissions of and lower facility bottlenecking in refineries. They added that since VAPEX is a non-thermal process, steam is not generated so, there will not be any transformation of water and clean natural gas to steam and greenhouse gas emissions. Alternatively, because of the nature of the VAPEX process, solvent gas recovery will reduce the costs and environmental effects.

One of the key parameters affecting the ultimate performance of VAPEX process is establishing a connection between the injection and production well. If there is a sound connection between the injection and production well the solvent chamber will evolve faster and the contact area between the solvent and heavy oil will be increased. The larger contact area between the heavy oil and solvent will result in higher heavy oil dilution and higher drainage rate. This will significantly affect the VAPEX process. This research is mainly focused on providing an extensive study of VAPEX process performance by considering the injection of propane in large-scale physical models with different heights. To achieve this goal, two different injection scenarios using propane and propane $/ \mathrm{CO}_{2}$ mixture as respective solvents were carried out, this will be discussed in more details throughout this paper. In this paper, the importance and effects of connection establishment in VAPEX process is studied extensively in two large scale physical models using different solvents. 


\section{METHODOLOGY}

A comprehensive experimental study was designed and carried out in order to investigate the effect of the connection between injection and production wells during the VAPEX process. To better represent and simulate the actual conditions, two large VAPEX models were modified and successfully used for these experiments.

\subsection{Experimental Set-Up}

For the VAPEX experiments, a comprehensive experimental study was conducted using two large scale physical models. This experimental set-up consists of four major units: a gas injection unit, the VAPEX physical models, a gas and liquid production unit and data acquisition unit.

The gas injection unit was composed of gas cylinders (propane and $\mathrm{CO}_{2}$ ), gas pressure regulators, digital pressure gauges, solvent injection valves, and Mass FlowMeters (MFM) calibrated specifically for each gas. In this study, VAPEX experiments were conducted under constant pressure. Propane and propane $/ \mathrm{CO}_{2}$ mixture were injected as the solvent through the pressure regulators to monitor and maintain the constant injection pressure. The solvent injection line was connected to MFM to record the rate of injection and the total volume of injected solvent. Another pressure gauge recorded pressure at the injection points of the physical models. It should be mentioned that each measuring device had a range of accuracy which is presented in Table 1. Two 2-D rectangular VAPEX models with the dimensions mentioned in Table 2 were used to carry out the experiments. These visual slab models were made of

TABLE 1

Accuracy of measuring device used in the experimental set-up

\begin{tabular}{c|c|c}
\hline Device & Manufacturer & Uncertainty \\
\hline Digital pressure gauge & Ashcroft & $\pm 0.5 \% \mathrm{kPa}$ \\
\hline Digital flow meter & Aalborg & $\pm 1 \% \mathrm{~mL} / \mathrm{min}$ \\
\hline Temperature controller & Dwyer & $\pm 1^{\circ} \mathrm{C}$ \\
\hline Wet test meter & Ritter & $\pm 0.2 \% \mathrm{~L} / \mathrm{h}$ \\
\hline
\end{tabular}

TABLE 2

Physical models dimensions

\begin{tabular}{c|c|c|c|c}
\hline $\begin{array}{c}\text { Physical } \\
\text { model }\end{array}$ & $\begin{array}{c}\text { Height } \\
(\mathrm{cm})\end{array}$ & $\begin{array}{c}\text { Length } \\
(\mathrm{cm})\end{array}$ & $\begin{array}{c}\text { Thickness } \\
(\mathrm{cm})\end{array}$ & $\begin{array}{c}\text { Volume } \\
\left(\mathrm{cm}^{3}\right)\end{array}$ \\
\hline Small & 24.5 & 20 & 5 & 2450 \\
\hline Large & 47.5 & 38 & 5 & 9025 \\
\hline
\end{tabular}

thick plexiglas plates with a stainless steel frame. The visual slabs limit the maximum operating pressure, as they were designed for pressures up to $1 \mathrm{MPa}$. However, their transparency was necessary for visual observation of the solvent injection process, specifically in terms of solvent chamber evolution. Figures 1 and 2 show the schematic and dimensions of the physical models as well as the cavity space of each model.

The fluid production unit included production control valves, digital pressure gauges, Back-Pressure Regulators (BPR), nitrogen gas cylinders, separators, Wet Test Meters (WTM) and oil sample collectors. Digital pressure gauges were mounted at the production points to monitor the outlet pressure.

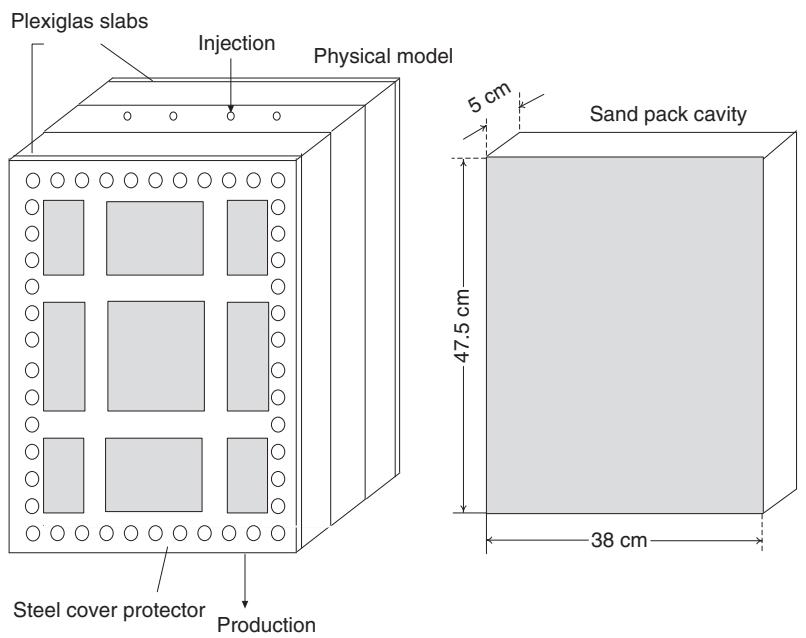

Figure 1

The schematic of the large physical model and its sand pack cavity.
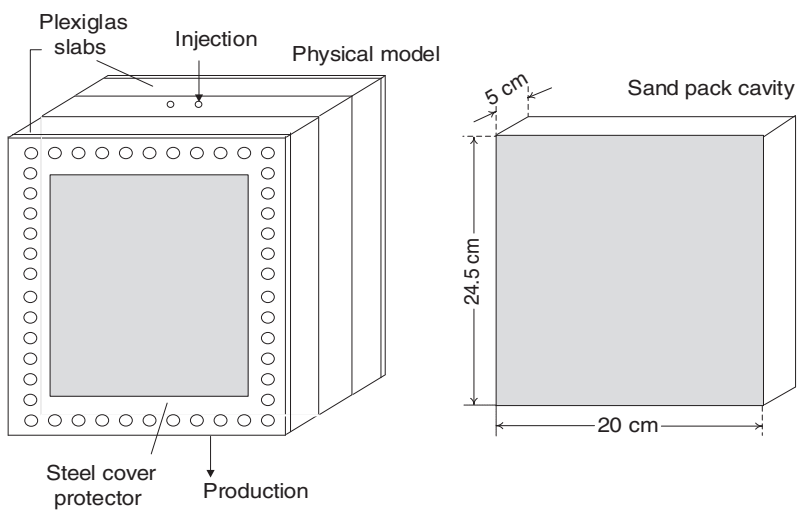

Figure 2

The schematic of the small physical model and its sand pack cavity. 


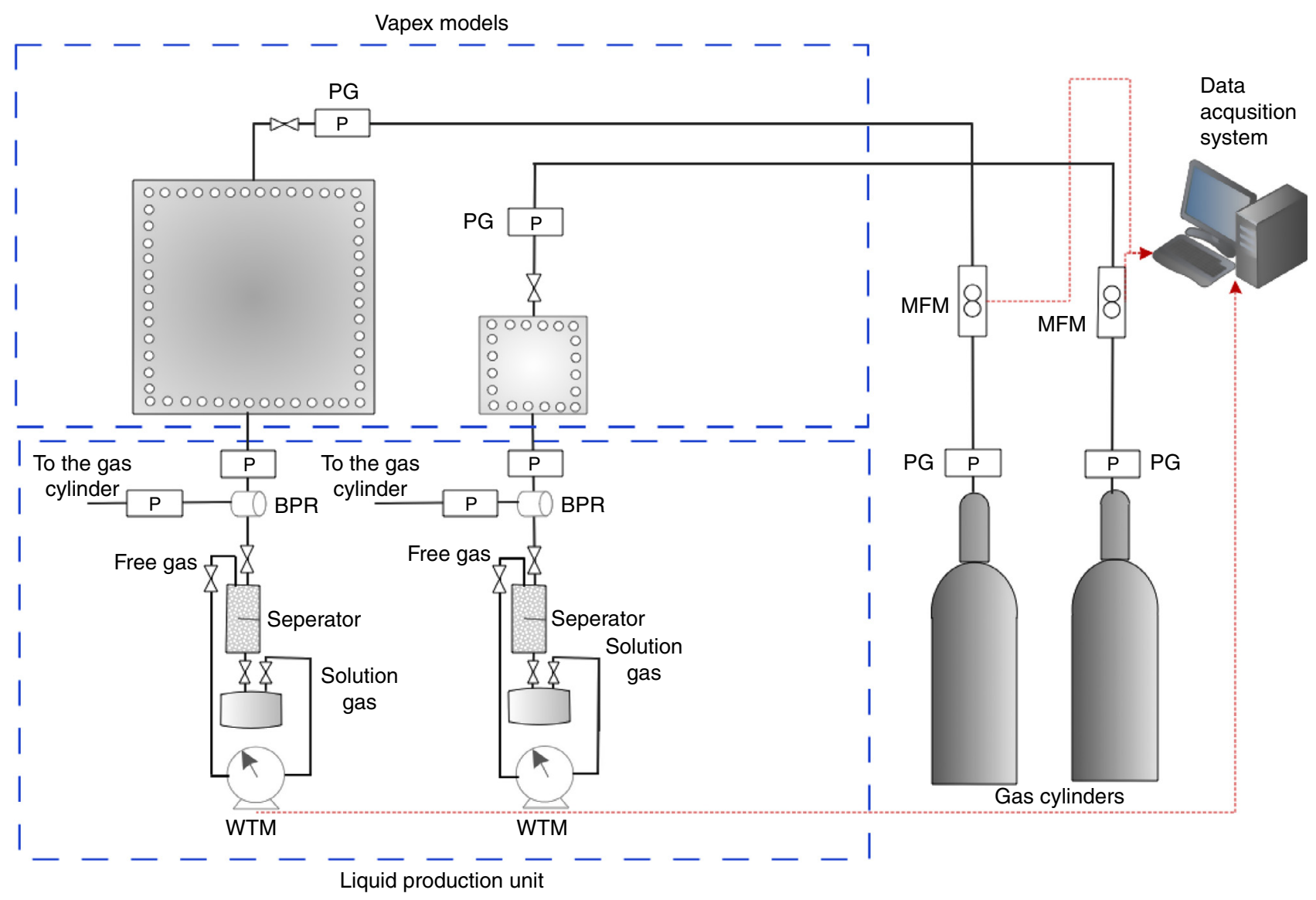

Figure 3

Schematic of the experimental setup.

The BPR were used to maintain the pre-specified pressure in each VAPEX model during the experiments. The produced oil and gas were collected in two separators below each physical model. The rate and total volume of the produced gas are accurately measured with two WTM.

During the course of experiments, different parameters were recorded at the data acquisition unit, which was composed of a computer as well as special ports, converters, and pulse generators. Figure 3 shows the schematic diagram of the designed experimental set-up.

\subsection{Experimental Procedure}

Each of the VAPEX experiments was performed in three major steps. The first step was preparation, in which, the model was packed with sand, pressure leaks were tested; the model was then vacuumed and saturated with oil. The next step was running the experiments, which included the continuous gas injection, monitoring the process, recording the data. The last step was unpacking and cleaning the model.

For the packing, the VAPEX models were set into horizontal position while one of the slabs on each model was bolted. The cavities of the VAPEX models were packed with dry Ottawa sand. Then, the gaskets, second plexiglas slabs, and steel protection covers were bolted in sequence and the models were set back to the vertical position. At this point, additional sand was added with a funnel through the top injection ports to pack the empty spaces. Ottawa sand \#530 was used to pack the VAPEX physical models. This white sand with a rounded grain shape is made of $99.88 \%$ Silicon Dioxide $\left(\mathrm{SiO}_{2}\right)$. The specific gravity of the sand used for this study was $2.65\left(\gamma_{\mathrm{H}_{2} \mathrm{O}}=1.0\right)$. Figure 4 shows the Particle Size Distribution (PSD) for Ottawa sand which was used for these experiments. After packing the models, the connections and required fittings, valves and piping were connected to the top and bottom ports of the physical models. Then, nitrogen was injected into the models at the 


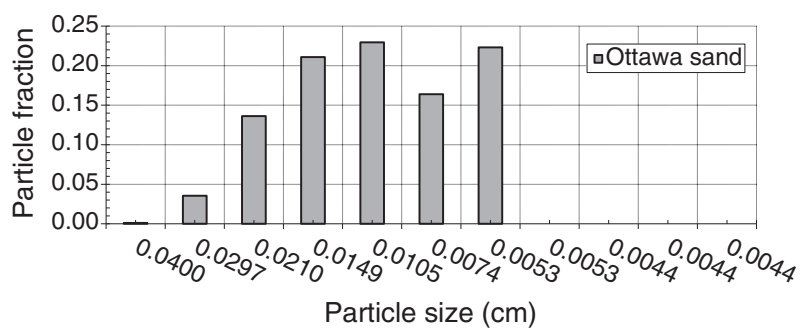

Figure 4

Particle Size Distribution (PSD) for \# 530 Ottawa sand.

maximum allowable operating pressure of the VAPEX models $(1 \mathrm{MPa})$ to conduct the pressure test and finally, the physical models were evacuated with a vacuum pump.

In this study, both models were saturated with heavy oil samples and no $S_{w c}$ was considered. Prior to oil injection, the sand pack was dried with pressurized air. To establish uniform oil saturation in the VAPEX models, the oil was injected into the VAPEX models through the bottom connection points. For this purpose, a high-pressure transfer cell was employed and connected to a syringe pump. Because of the pressure constraints of the physical models, the injection rate was very low, which made the oil saturation process very slow. It took about 2 to 3 days to saturate the small model and about 6 to 7 days to saturate the large model. The compositional analysis of the heavy oil sample was obtained by using the simulated distillation method. The results are shown in Table 3. As it can be observed, there are no hydrocarbon components under $\mathrm{C}_{9}$, and that the weight percent of $\mathrm{C}_{50+}$ is $10.54 \%$.

Eight VAPEX experiments were carried out, in which, propane and mixture of propane $/ \mathrm{CO}_{2}$ were injected in two VAPEX models with different drainage heights. Once the models were saturated, the solvent injection line was connected to the top connection of the VAPEX models. The solvent was injected at constant pressure from the gas cylinders to MFM and then to the VAPEX models at a pre-specified constant pressure. The operating conditions for the conducted experiments are presented in Table 4. The flow rates and total injected solvent volumes were recorded by the MFM. Two injection scenarios were carried out to observe the effect of connection between the injection and production well. In the first scenario, the solvent was injected to the physical models at the operating pressure while the production pressure was atmospheric pressure and the gas and oil production was monitored carefully. Once, the gas breakthrough was monitored the production pressure was set to the operating pressure to eliminate the pressure difference and start producing due to the gravity drainage.
TABLE 3

Compositional analysis result of the injection heavy oil at $21^{\circ} \mathrm{C}$

\begin{tabular}{|c|c|c|c|}
\hline $\begin{array}{l}\text { Carbon } \\
\text { number }\end{array}$ & Mol.\% & $\begin{array}{l}\text { Carbon } \\
\text { number }\end{array}$ & Mol.\% \\
\hline $\mathrm{C} 1$ & 0.0 & $\mathrm{C} 21$ & 2.75 \\
\hline $\mathrm{C} 2$ & 0.0 & $\mathrm{C} 22$ & 1.68 \\
\hline $\mathrm{C} 3$ & 0.0 & $\mathrm{C} 23$ & 2.11 \\
\hline $\mathrm{C} 4$ & 0.0 & $\mathrm{C} 24$ & 1.83 \\
\hline C5 & 0.0 & $\mathrm{C} 25$ & 1.75 \\
\hline C6 & 0.0 & $\mathrm{C} 26$ & 1.56 \\
\hline $\mathrm{C} 7$ & 0.0 & $\mathrm{C} 27$ & 1.61 \\
\hline $\mathrm{C} 8$ & 0.0 & $\mathrm{C} 28$ & 1.61 \\
\hline C9 & 3.38 & $\mathrm{C} 29$ & 1.32 \\
\hline $\mathrm{C} 10$ & 11.17 & $\mathrm{C} 30$ & 1.25 \\
\hline C11 & 12.95 & $\mathrm{C} 31$ & 1.20 \\
\hline $\mathrm{C} 12$ & 5.76 & $\mathrm{C} 32$ & 1.16 \\
\hline $\mathrm{C} 13$ & 3.22 & C33 & 0.80 \\
\hline C14 & 3.02 & C34 & 0.76 \\
\hline $\mathrm{C} 15$ & 3.60 & $\mathrm{C} 35$ & 0.97 \\
\hline C16 & 3.19 & C36 & 1.02 \\
\hline $\mathrm{C} 17$ & 3.47 & C37 & 0.61 \\
\hline $\mathrm{C} 18$ & 3.31 & C38 & 0.57 \\
\hline C19 & 2.93 & C39 & 0.95 \\
\hline $\mathrm{C} 20$ & 2.59 & $\mathrm{C} 40+$ & 15.89 \\
\hline
\end{tabular}

Molecular weight: $502, \mu_{\text {oil }}=5650 \mathrm{mPa} . \mathrm{s}$ at $21^{\circ} \mathrm{C}$

For the second scenario, the pressure at the production point was implemented after that the connection between the injection and production well was visually observed. It took more injection time and a larger amount of solvent was produced before exerting the back-pressure at the production well. Once the oil was produced through the BPR, it was collected in the separators and by reading from the calibrated visual separators; the cumulative produced oil was recorded regularly during the course of the experiments. The produced solvent was separated, and then, from the top valves on each of the separators, the produced solvent was passed through the WTM to measure the total volume of produced solvent.

After running each VAPEX test, separate asphaltene content measurement experiments were carried out. For this purpose, four different samples were picked from four different locations of the physical models (Fig. 5), and the asphaltene 
TABLE 4

Operating conditions of the conducted experiments

\begin{tabular}{c|c|c|c|c|c|c|c|c}
\hline Test No. & $\begin{array}{c}\text { Physical } \\
\text { model }\end{array}$ & Solvent & Porosity (\%) & $\begin{array}{c}\text { Permeability } \\
(\mathrm{D})\end{array}$ & $\begin{array}{c}\text { Pressure } \\
(\mathrm{KPa})\end{array}$ & $\begin{array}{c}\text { Temperature } \\
\left({ }^{\circ} \mathrm{C}\right)\end{array}$ & $\begin{array}{c}\text { Oil density } \\
\left(\mathrm{kg} / \mathrm{m}^{3}\right)\end{array}$ & $\begin{array}{c}\text { Oil viscosity } \\
(\mathrm{mPa} . \mathrm{s})\end{array}$ \\
\hline 1 & Small & Propane & 36.9 & 5.32 & 700 & 21 & 971.53 & 5650 \\
\hline 2 & Large & Propane & 39.3 & 6.51 & 700 & 21 & 971.53 & 5650 \\
\hline 3 & Small & Propane/ $\mathrm{CO}_{2}$ & 40.7 & 5.12 & 850 & 21 & 971.53 & 5650 \\
\hline 4 & Large & Propane/ $\mathrm{CO}_{2}$ & 41.8 & 5.88 & 850 & 21 & 971.53 & 5650 \\
\hline 5 & Small & Propane & 42.2 & 8.78 & 700 & 21 & 971.53 & 5650 \\
\hline 6 & Large & Propane & 43.1 & 9.12 & 700 & 21 & 971.53 & 5650 \\
\hline 7 & Small & Propane $/ \mathrm{CO}_{2}$ & 41.8 & 8.64 & 850 & 21 & 971.53 & 5650 \\
\hline 8 & Large & Propane $/ \mathrm{CO}_{2}$ & 42.4 & 8.87 & 850 & 21 & 971.53 & 5650 \\
\hline
\end{tabular}

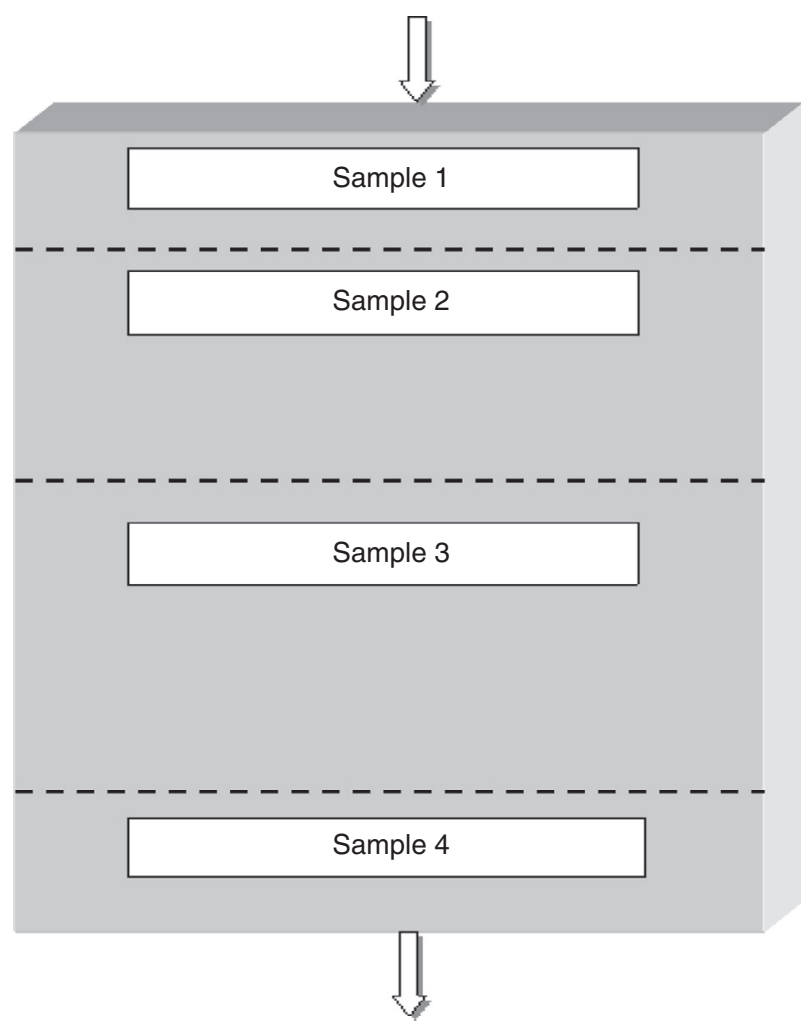

Figure 5

Schematic of the locations of each heavy oil sample in the physical models.

content was measured for each sample individually to monitor the asphaltene deposition at different locations during the process. To measure the asphaltene content of each sample, at first the remaining oil in each sample obtained from the sand-packs should be separated from the sand.
The asphaltene content of each sample was then measured using the standard ASTM D2007-03 method. The precipitant used here was $n$-pentane, which was added to the oil sample and stirred thoroughly. Then, the mixture was filtered through $0.2 \mu \mathrm{m}$ Whatman No. 5 filter paper; this process was continued until clean liquid drainage was monitored from the filter paper. Afterward, the asphaltene precipitant on the filter paper was kept in the air bath for one day to dry completely and the final weight of the asphaltene precipitate was recorded to measure the asphaltene content of each sample.

\section{RESULTS AND DISCUSSION}

Eight VAPEX experiments were carried out in two large scale physical models. Test numbers 1 to 4 were carried out following the first injection scenario, and test numbers 5 to 8 were conducted following the second injection scenario.

\subsection{First Injection Scenario}

Figure 6 shows the recovery factor after injecting propane as the solvent in the physical models for the first injection scenario. The ultimate recovery factor of about $80 \%$ of original oil in place was observed after injecting propane as the solvent in the small model, however the recovery factor achieved in large model was significantly lower and it was about $50 \%$ of original oil in place. Here, the ultimate recovery factor in the small model was higher and the process seemed to be faster as well. This disparity may be the result of well configuration and the poor connection between the injection and production wells, therefore the solvent chamber moved faster in the small physical model in comparison to the large model with a greater drainage height. 


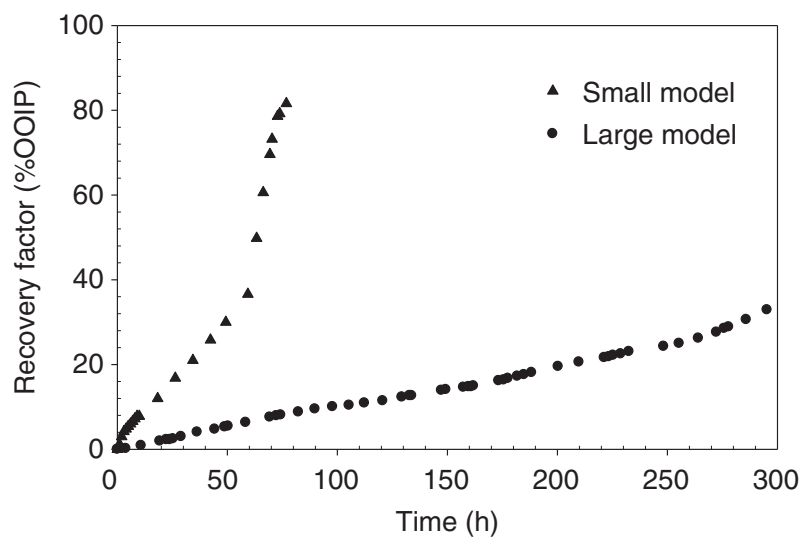

Figure 6

The recovery factor after propane injection in VAPEX models (first injection scenario).

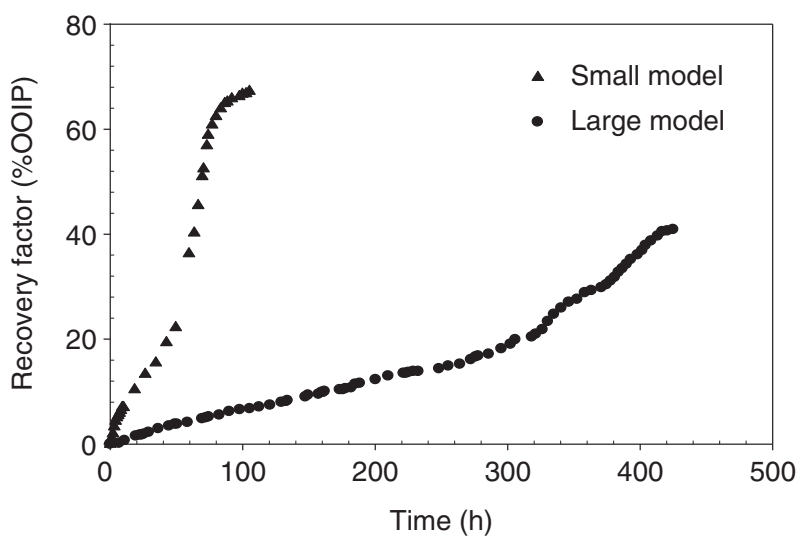

Figure 7

The recovery factor after propane/ $\mathrm{CO}_{2}$ injection in VAPEX models (first injection scenario).

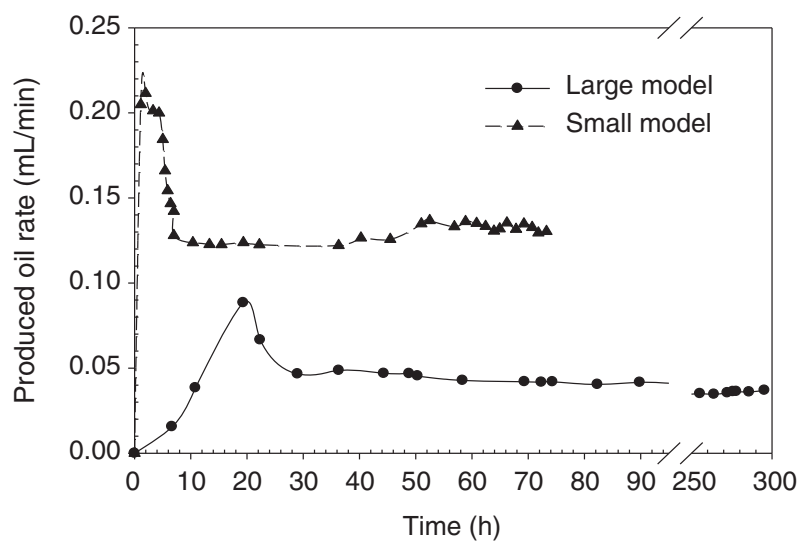

Figure 8

Produced oil rate after propane injection in VAPEX models (first injection scenario).

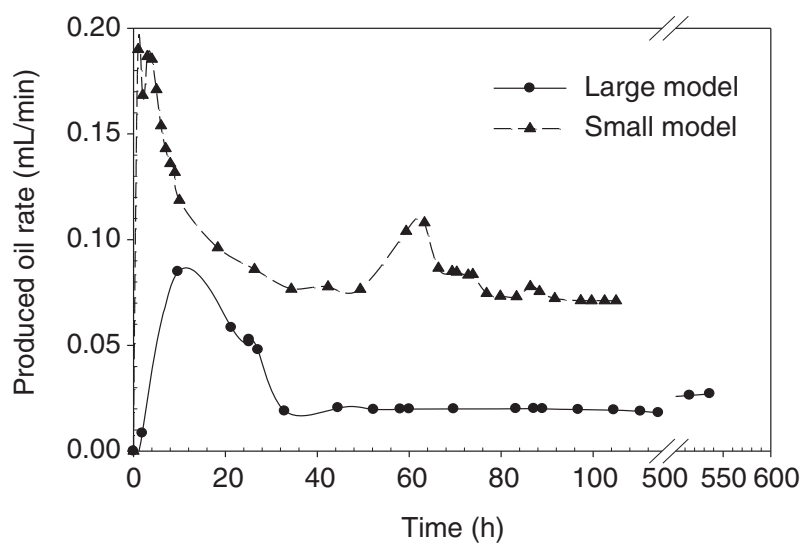

Figure 9

Produced oil rate after first propane/ $\mathrm{CO}_{2}$ injection in VAPEX models (first injection scenario).
The same trend was observed when a mixture of propane/ $\mathrm{CO}_{2}$ was used as the solvent for the VAPEX process. As it can be seen in Figure 7, the recovery factor of about $65 \%$ of original oil in place was observed in the small model, while this parameter was about $40 \%$ of original oil in place in the large model. However, the more significant disparity was observed while comparing the results about the produced oil rate. It was expected to observe higher drainage rates in the large model because of the greater drainage height. But as it can be seen in Figures 8 and 9, the produced oil rate was higher in the small model compared to the large model. The stabilized drainage rate after propane injection was observed to be about $0.12 \mathrm{~mL} / \mathrm{min}$ for the small model, and about $0.04 \mathrm{~mL} / \mathrm{min}$ for the large model. For the case of propane $/ \mathrm{CO}_{2}$ injection, the stabilized drainage was found to be about $0.08 \mathrm{~mL} / \mathrm{min}$ for the small model, and $0.02 \mathrm{~mL} / \mathrm{min}$ for the large model. At times, there were sudden oil production rate fluctuations, which can be due to pressure disturbance during gas injection; though, different researchers have also observed these sudden production rate changes (Yazdani and Maini, 2005; Ahmadloo et al., 2011). Along these lines, Yazdani and Maini (2005) suggested that this fluctuation could be the result of asphaltene precipitation near production points. In such instances, the production port blockage caused by asphaltene deposition will lead to a surge of oil that may cause fluctuations. 


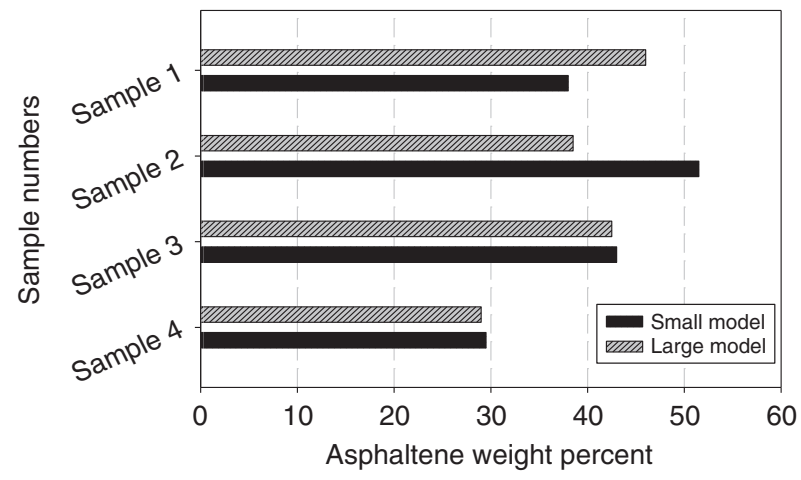

Figure 10

Effect of drainage height on asphaltene precipitation at different locations in small and large models after propane injection (first injection scenario).

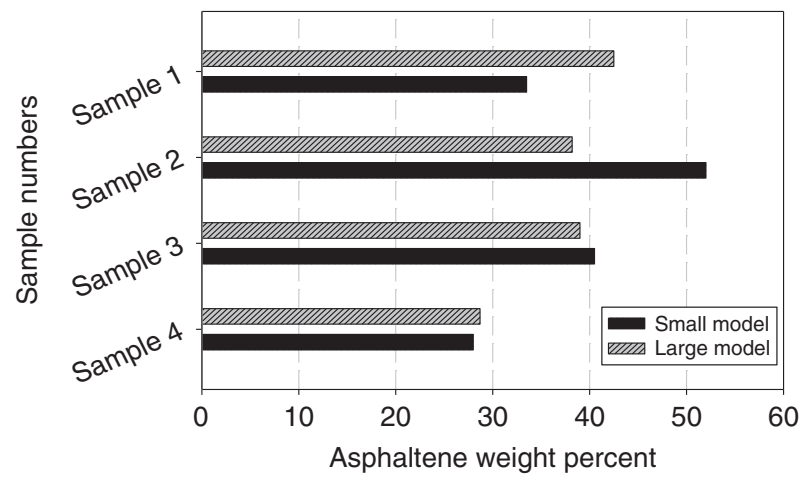

Figure 11

Effect of drainage height on asphaltene precipitation at different locations in small and large models after propane $/ \mathrm{CO}_{2}$ injection (first injection scenario).
After measuring the asphaltene content of the injected oil and taking different samples from different locations of the physical models, noticeable asphaltene precipitation was observed specifically near the injection ports in both small and large models. Figure 10 shows the asphaltene content of different samples for the small and large models after injecting propane following the first injection scenario. It was observed that the highest asphaltene deposition occurred at the points close to the injection wells and the solvent/oil interface, where the solvent and the oil had the highest contact time with each other; however the lowest asphaltene deposition was found to occur close to the production wells. The asphaltene content close to the injection well was $38 \%$ and $46 \%$ for the small and large models respectively. From the solvent type point of view, by referring to Figure 11, the same trend was observed after propane $/ \mathrm{CO}_{2}$ mixture, but overall asphaltene deposition was observed to be higher in the case of propane injection.

Finally, an Image Analysis (IA) was carried out to monitor the solvent chamber evolution after each injection scenario. For this purpose, software with a graphical user interface was coded using $\mathrm{C} \#$ to analyse the images from the small and large physical models. Because of the limitations we had in the laboratory with the large models, the angle and zooming of the images changed for certain images, therefore commercial IA software did not give accurate results.

Figure 12 shows the chamber evolution after implementing the first injection scenario; these pictures are processed with the developed IA software. In these pictures, the solvent and oil zones appear distinctively during the experiments, in which the untouched zone is shown with the darker color, while the swept zone is shown with light grey color. Of note, a similar shape was observed in both physical models.
The chamber forms and develops toward the sidewalls and then moves downward with reduced available drainage height. It was also observed that the solvent chamber fell down faster on the left wall until the end of the experiments when it was fully developed and it reached the bottom boundary of the physical models.

\subsection{Second Injection Scenario}

After following the second injection scenario to establish a more confident connection between the injection and production wells, the results were different and higher productions rates were observed in the larger model with greater drainage height. The process was faster, and better areal sweep efficiency was observed which will be discussed in more details later in this paper. Figure 13 shows the recovery factor after injecting propane as the solvent in the physical models for the second injection scenario. As it can be seen in this figure, the recovery factor is almost the same for both the small and large physical models. The ultimate recovery factor of about $75 \%$ of original oil in place was observed after injecting propane as the solvent. The same trend was observed when a mixture of propane/ $\mathrm{CO}_{2}$ was used as the solvent for the VAPEX process. However the ultimate recovery factor showed a little bit of difference, as it can be seen in Figure 14 . The recovery factor of about $54 \%$ of original oil in place was observed in the small model, while the ultimate recovery factor was about $52 \%$ of original oil in place in the large model. Although the difference is not that much significant, but it can be due to the complex effects of introducing a carrier gas $\left(\mathrm{CO}_{2}\right.$ in this case) to the injection solvent. The main observation was achieved when the stabilized drainage rates were monitored. According to the results 

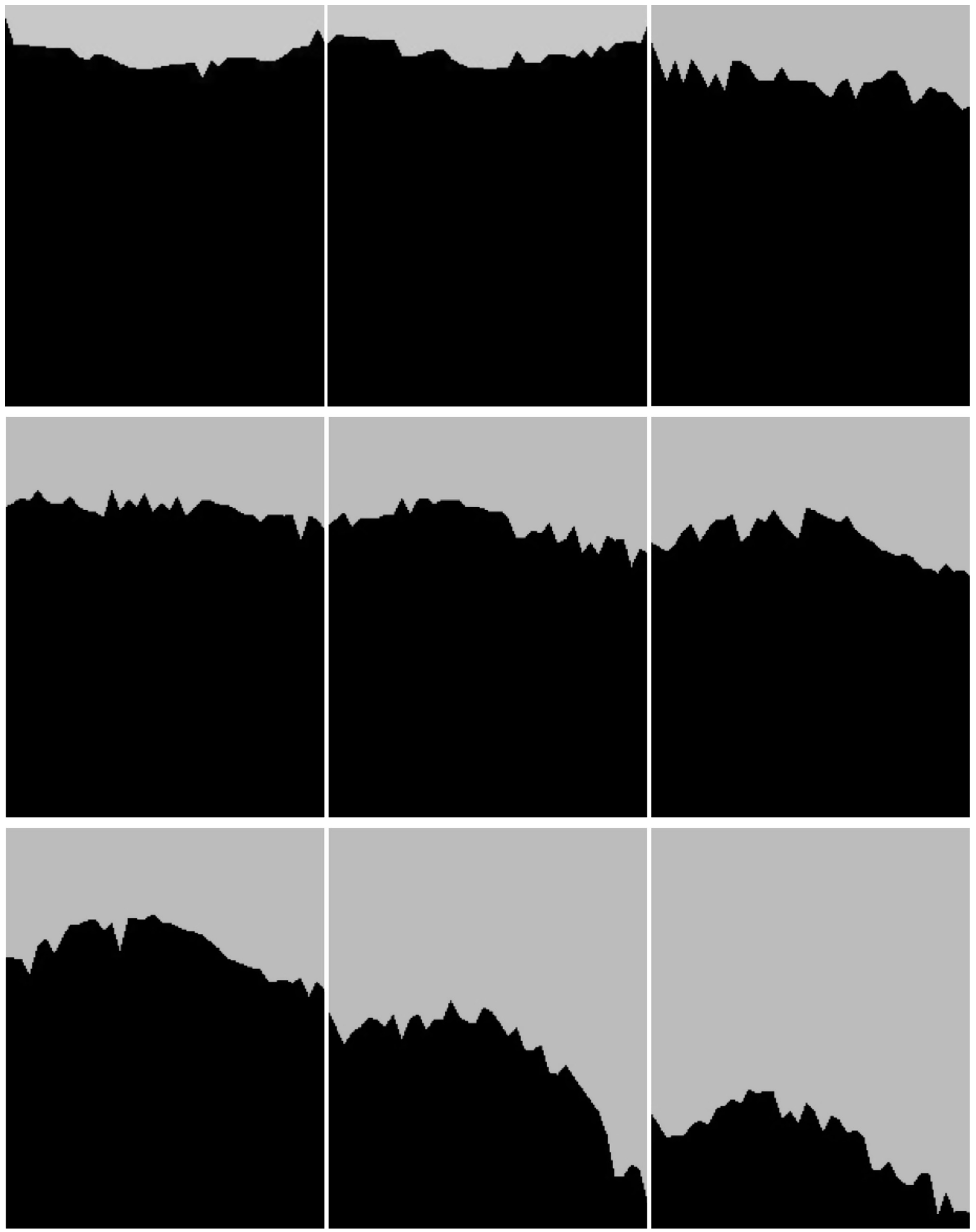

Figure 12

Solvent chamber evolution in small model after propane injection (first injection scenario). 


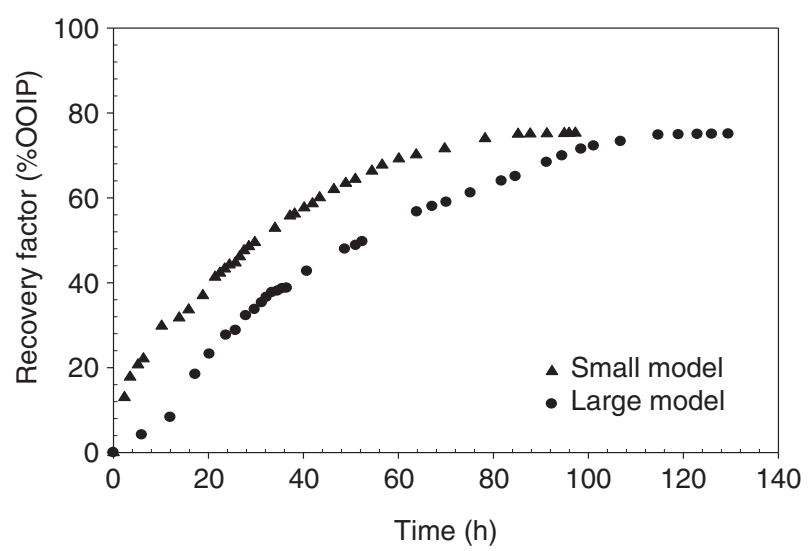

Figure 13

The recovery factor after propane injection in VAPEX models (second injection scenario).

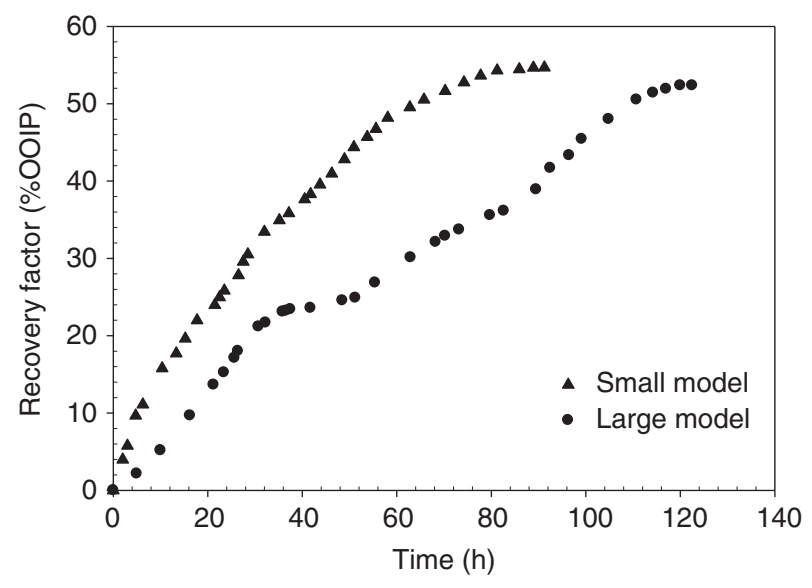

Figure 14

The recovery factor after propane/ $\mathrm{CO}_{2}$ injection in VAPEX models (second injection scenario).

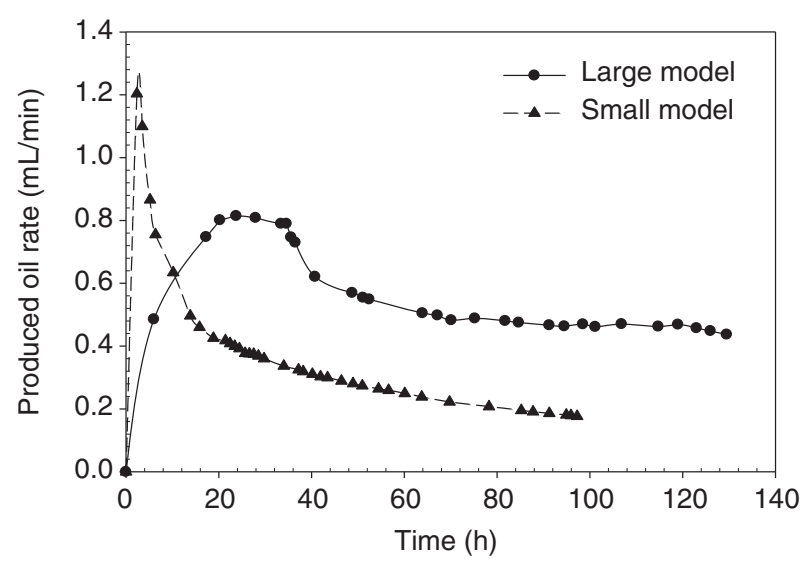

Figure 15

Produced oil rate after propane injection in VAPEX models (second injection scenario).

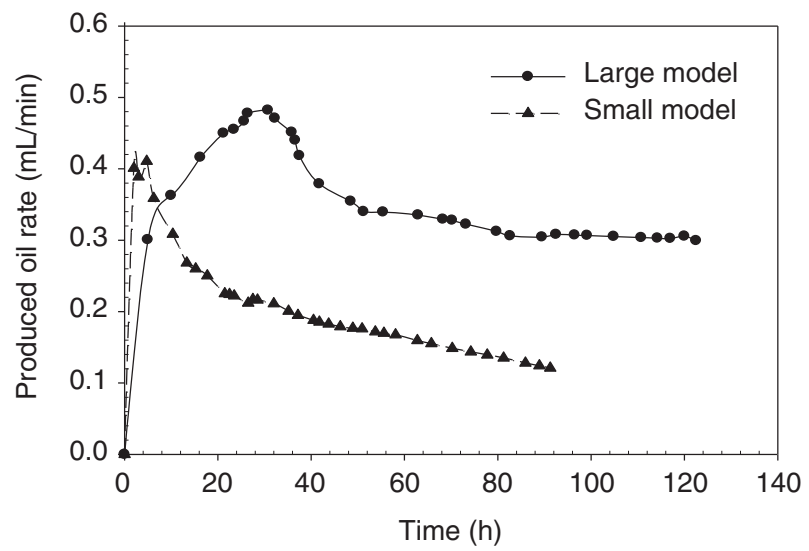

Figure 16

Produced oil rate after first propane/ $\mathrm{CO}_{2}$ injection in VAPEX models (second injection scenario).

obtained in Figures 15 and 16, the produced oil was higher in the large model compared to the small model. By following the second injection scenario and establishing a strong connection between the injection and production wells, the positive effect of drainage height was clearly observed. The stabilized drainage rate after propane injection was found to be about $0.22 \mathrm{~mL} / \mathrm{min}$ for the small model, and about $0.50 \mathrm{~mL} / \mathrm{min}$ for the large model. The more strong connection between the injection and production wells slightly improved the recovery performance of the process in the small model, but it significantly boosted the process in the large model. For the case of propane/ $\mathrm{CO}_{2}$ injection, the stabilized drainage rate was found to be about $0.15 \mathrm{~mL} / \mathrm{min}$ for the small model, and $0.33 \mathrm{~mL} / \mathrm{min}$ for the large model. The performance of the process was even more improved in this case compared to the same solvent injection in the first injection scenario. These positive results confirmed the efficiency of introducing carrier gases such as $\mathrm{CO}_{2}$ to decrease the solvent inventory costs and to increase the pressure range of applicability of the process.

Figures 17 and 18 show the asphaltene content of different samples for the small and large models after injecting propane and propane/ $\mathrm{CO}_{2}$ following the second injection scenario, respectively. Compared to the first injection scenario, less asphaltene depositions were observed at different locations of the physical models for both propane and propane $/ \mathrm{CO}_{2}$ as injection solvents. For instance, the asphaltene content for sample one was found to be $40 \%$ for the large model after injecting propane, while at the same location asphaltene content of $46 \%$ was observed after conducting the first injection scenario. The more efficient connection between the injection and production well decreased the ultimate recovery process and the recovery process took 


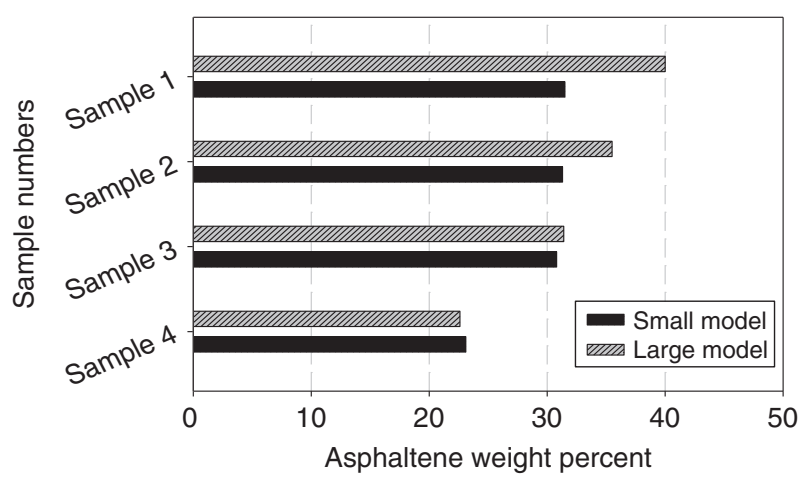

Figure 17

Effect of drainage height on asphaltene precipitation at different locations in small and large models after propane injection (second injection scenario).

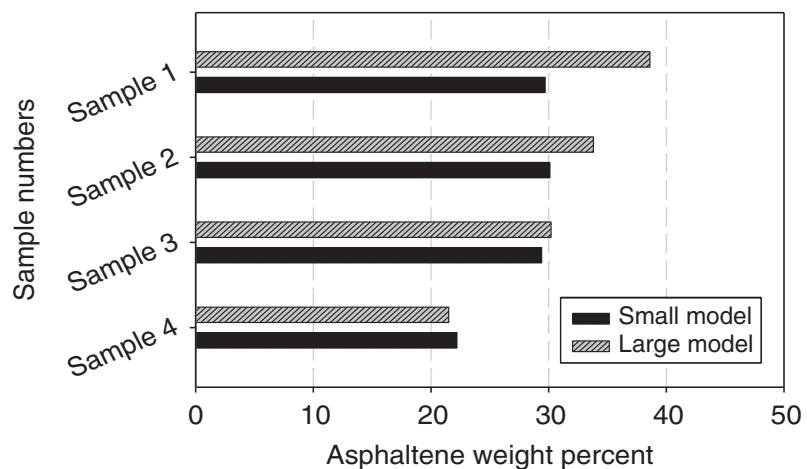

Figure 18

Effect of drainage height on asphaltene precipitation at different locations in small and large models after propane/ $\mathrm{CO}_{2}$ injection (second injection scenario).

TABLE 5

Produced oil properties

\begin{tabular}{|c|c|c|c|c|c|}
\hline Test No. & Physical model & Solvent & Viscosity (mPa.s) & Density $\left(\mathrm{kg} / \mathrm{m}^{3}\right)$ & Molecular weight \\
\hline 1 & Small & Propane & 1235 & 957.51 & 493 \\
\hline 2 & Large & Propane & 644 & 952.75 & 507 \\
\hline 3 & Small & Propane $/ \mathrm{CO}_{2}$ & 1950 & 954.48 & 501 \\
\hline 4 & Large & Propane $/ \mathrm{CO}_{2}$ & 1500 & 953.71 & 506 \\
\hline 5 & Small & Propane & 999 & 853.50 & 509 \\
\hline 6 & Large & Propane & 469 & 938.17 & 469 \\
\hline 7 & Small & Propane/ $\mathrm{CO}_{2}$ & 1480 & 944.46 & 505 \\
\hline 8 & Large & Propane $/ \mathrm{CO}_{2}$ & 1160 & 954.41 & 503 \\
\hline
\end{tabular}

place faster, therefore the contact time between the oil and sample was decreased, which resulted in less asphaltene deposition. Other than that, the same trend as the first injection scenario was observed for the small and large models implementing each injection solvent.

Fluid properties of the produced fluid were measured after each test to observe the effect of different injection scenarios and the type of injection solvent on the produced fluid. Table 5 shows viscosity, molecular weight, and oil density of the produced oil. The results show two effective parameters as mentioned before, one is the type of the injection solvent used, and the other one is the connection establishment between the injection and production. Propane injection has significantly diluted the original oil and reduced its viscosity in both injection scenarios. However, the decrease in the viscosity is more noticeale in the second injection scenario, for instance for the case of propane injection, the first injection scenario resulted in the reduction of original oil viscosity from $5650 \mathrm{mPa}$.s to $644 \mathrm{mPa}$.s, while it decreased from $5650 \mathrm{mPa}$.s to $469 \mathrm{mPa}$.s for the second injection scenario in the large VAPEX model. Additionally, hydrocarbon components of the produced oil were measured and compared with the original oil to observe the produced oil properties in more details. Figure 19 shows the compositional analysis of the produced oil after propane and propane $/ \mathrm{CO}_{2}$ injection for both injection scenarios in small and large models. During the first hours of injecting solvent, a narrow path between the injection and connection wells was monitored showing the flow of solvent toward the low pressure production well. However, once the back-pressure was inserted at the production well, this path was no longer visible, on the other hand the solvent chamber started to 


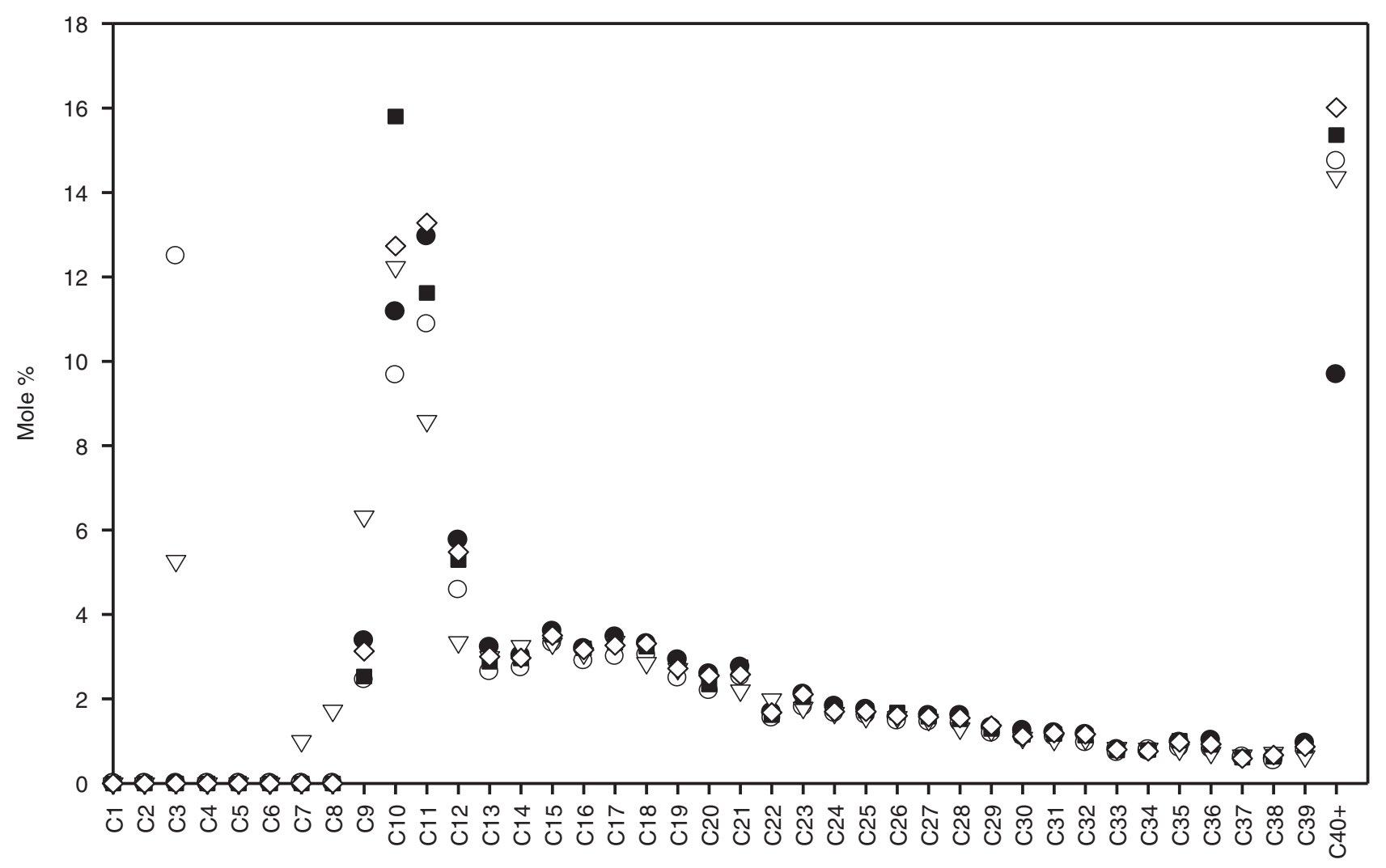

Carbon number

Injection oil

Produced oil after propane_2 injection in small model

$\nabla$ Produced oil after propane_2 injection in large model

- Produced oil after propane_1 injection in small model

$\diamond$ Produced oil after propane_1 injection in large model

Figure 19

Compositional analysis of the produced oil.

evolve in a conical shape. During the experiments, shape of the chamber was recorded using a digital camera, and the processed images are shown in Figure 20.

\section{CONCLUSIONS}

An extensive experimental study involving injecting different solvents in two large-scale visual physical models was carried out to investigate the effect of injection-production wells connection on the recovery performance of VAPEX process. In this research novel results were obtained on the significant effects of the connection between the production and injection wells in the large model, therefore it is expected that in a field scale project this factor would be even more prominent. The following major conclusions were drawn during this research:

- when there was an initial poor connection between the injection and production well, the stabilized drainage rate was found to be lower in the large model with a greater drainage rate. After injecting propane, the stabilized drainage rate was about $0.12 \mathrm{~mL} / \mathrm{min}$ and $0.04 \mathrm{~mL} / \mathrm{min}$ for the small and large models respectively. For the case of propane $/ \mathrm{CO}_{2}$ injection, the stabilized drainage rate was $0.08 \mathrm{~mL} / \mathrm{min}$ and $0.02 \mathrm{~mL} / \mathrm{min}$ for the small and large models respectively;

- by establishing a strong connection between the injectionproduction wells, the positive effect of drainage height 

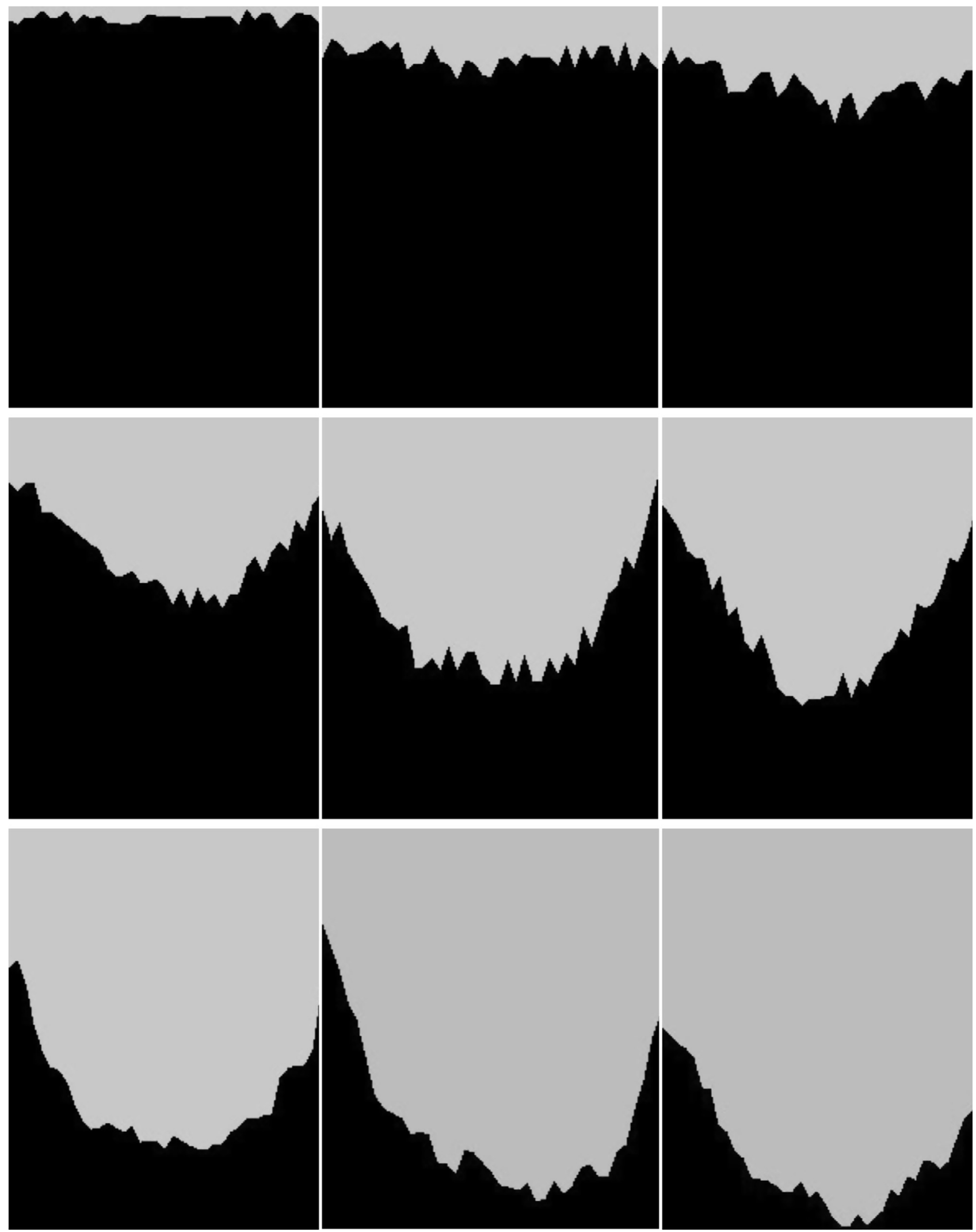

Figure 20

Solvent chamber evolution in small model after propane injection (second injection scenario). 
was observed and the drainage rate was found to be higher in the large model. Propane injection resulted in a drainage rate of $0.50 \mathrm{~mL} / \mathrm{min}$ and $0.22 \mathrm{~mL} / \mathrm{min}$ for the large and small models, respectively. The same trend was observed after injecting a mixture of propane $/ \mathrm{CO}_{2}$ as the solvent, and the stabilized drainage rate was found to be $0.33 \mathrm{~mL} / \mathrm{min}$ for the large model, while it was $0.15 \mathrm{~mL} / \mathrm{min}$ in the small model;

- better connection between the injection and production wells decreased the recovery process time significantly which directly affected the asphaltene deposition in both small and large models. Less asphaltene deposition was observed in both models after implementing the second injection scenario. However, from the solvent point of view, using propane resulted in more asphaltene deposition at different locations of the physical models.

\section{ACKNOWLEDGMENTS}

We would like to acknowledge the financial support from the University of Regina Faculty of Graduate Studies and Research and Natural Sciences and Engineering Research Council (NSERC) Canada.

\section{REFERENCES}

Abukhalifeh H., Upreti S.R., Lohi A. (2011) Permeability effect on the concentration-dependent propane dispersion coefficient in VAPEX, International Journal of Oil, Gas and Coal Technology 4, 11, 64-78.

Ahmadloo F., Asghari K., Henni A., Freitag N.P. (2011) Experimental results and analytical modeling of solvent leaching gravity drainage phenomenon in heavy oil reservoirs, SPE Annual Conference and Exhibition, Denver, Colorado, USA, 30 Oct.2 Nov.

Allen J.C. (1974) Gaseous solvent heavy oil recovery, US Patent 1027851 .
Allen J.C. (1976) Multiple solvent heavy oil recovery method, US Patent 3954141.

Butler R.M., Jiang Q. (2000) Improved recovery of heavy oil by VAPEX with widely spaced horizontal injectors and producers, Journal of Canadian Petroleum Technology 39, 1, 48-56.

Butler R.M., Jiang Q. (1996) Selection of well configuration in VAPEX process, SPE Conference 37145, Calgary, Canada AB, 18-20 Nov.

Butler R.M., Mokrys I.J. (1991) A new process (VAPEX) for recovering heavy oils using hot water and hydrocarbon vapour, Journal of Canadian Petroleum Technology 30, 1, 97-106.

Butler R.M., Mokrys I.J. (1989) Solvent analogue model of steam-assisted gravity drainage, AOSTRA Journal of Research $\mathbf{5}$, $1,17-32$.

Das S.K. (1995) In situ recovery of heavy oil and bitumen using vapourized hydrocarbon solvents, $P h D$ Thesis, University of Calgary.

James L.A., Rezaie N., Chatzis I. (2007) VAPEX, warm VAPEX, and hybrid VAPEX - the state of enhanced oil recovery for in situ heavy oils in Canada, Journal of Canadian Petroleum Technology 47, 4, 1-7.

Luhning R.W., Das S.K., Bakker J., Engleman J.R., Wong S., Fisher L.J., Grabowski J., Sullivan L.A., Boyle H.A. (2003) Full scale VAPEX process - Climate change advantage and economic consequences, Journal of Canadian Petroleum Technology 42, 2 , 29-34.

Roopa I., Dawe R.A. (2007) VAPEX - Gravity-assisted film drainage for heavy oil recovery, Journal of Petroleum Science and Technology 25, 5, 645-658.

Yazdani A. (2007) Physical and numerical modeling of permeability and drainage height effects in VAPEX, $P h D$ Thesis, University of Calgary.

Yazdani A., Maini B.B. (2005) Effect of drainage height and grain size on production rates in the Vapex process: Experimental study, SPE Reservoir Engineering Journal 8, 3, 205-213.

Manuscript submitted in March 2014 Manuscript accepted in December 2015

Published online in March 2015

Cite this article as: M. Mohammadpoor and F. Torabi (2016). Effect of Wells' Connectivity Enhancement on the Performance of Vapor Extraction (VAPEX) Process, Oil Gas Sci. Technol 71, 26. 